\title{
Experimental Investigation on Shell Footing Models Employing High-Performance Concrete
}

\author{
R. Rinaldi ${ }^{1(\bowtie)}$, M. Abdel-Rahman ${ }^{2}$, and A. Hanna ${ }^{3}$ \\ ${ }^{1}$ CN Canada, Montreal, Canada \\ remo.rinaldi@cn.ca \\ ${ }^{2}$ Housing \& Building National Research Center, Cairo, Egypt \\ rahman.mohamed@mail.com \\ ${ }^{3}$ Concordia University, Montreal, Canada \\ hanna@civil.concordia.ca
}

\begin{abstract}
Shell foundations are increasingly adopted around the world as an economic alternative to traditional flat foundations. Evidence of increased bearing capacity and reduction in settlement behavior exhibited by shell footings, coupled with their high potential resistance to seismic loading and sustained lateral earth pressure is valuable in terms of their geotechnical response. Nevertheless, practical use of shell footings is trailing behind conventional foundation structures due to lagging research on the performance and application of these foundations.

The objective of this paper is to present the results of experimental modeling on bearing capacity and settlement of shell foundations. Scaled prototypes footing models were developed and tested to evaluate the geotechnical behavior of the shell footing. The study focused on the effect of the parameters govern the performance of this foundations. Contact pressure was measured at several loading conditions namely; working load and ultimate state. Moreover, shell footing and flat models were casted employing high-strength polymeric concrete (UHPFRC). Experimental investigation tests show on average 40-45\% higher load-carrying capacity than its flat counterparts.
\end{abstract}

\section{Introduction}

On account of their streamlined form, use of shells as a foundation geometry over traditionally shaped mass structures has grown steadily since their inception in the early nineteen-fifties. Shell footings have evolved from primitive brick-arched constructions to complex hyperbolic, pyramidal and folded-plate forms particularly in upright orientations gaining significant attention post World War II.

Agarwal and Gupta [1] conducted experimental tests on conical, hyper and their plain counterparts on sand. Shell configuration combined with shell-soil interface roughness was determined to play key roles in the increased bearing capacity. Hanna and Abdel-Rahman [2] investigated the bearing capacity and settlement of conical, triangular and pyramidal shells as compared to flat circular and square shapes under plain strain conditions. A $40 \%$ increase in bearing capacity for the peak angle of $60^{\circ}$ 
was found over that of the flat model on account of deeper shear failure surface. Hanna and Abdel-Rahman and Iyer and Rao [2-4] performed experimental tests to investigate the bearing capacity of shell foundations as compared to their flat counterparts. The shells improved bearing capacity was found to be due to the stiffness and geometry of the shell models.

Kurian et al. [5, 6] also conducted experimental tests on various shell geometries with similar conclusions. Kurian and Mohan [7, 8], Kurian and Shah [9], and Rinaldi [10] reported on the contact pressure distribution for various shell shapes. Results were indicative of a non-uniform contact pressure distribution along the shell-soil interface. However, presently shell design is based on membrane theory where the contact pressures are assumed uniform.

The previous studies have undoubtedly shown these latest shell newcomers outperform conventional flat footings and provide beneficial alternative from an economic perspective. Their desirable structurally efficient form relies on continuity of its thin-slab material as opposed to mass performing exceptionally well particularly when heavy super-structural loads are to be transmitted to weak bearing soil. Shells are by no means limited to just a few simple geometries. This mindset certainly has restricted exploration and thus impeded benefits offered by shells and research of new shell shapes. Typical geometries studied in the literature by preceding scholars and researchers have typically been pyramidal, conical, spherical and hyperbolic shapes.

\section{Experimental Investigation}

The experimental investigation aims to study the performance of scaled models of inverted triangular shells in stochastic sand. Model tests conducted aim at developing shell behaviour under monotonic loading conditions. The contact pressures obtained for varied conditions will help explain the influence certain shell parameters have on the behaviour of shell footings. The objective is to study the influence of shell angles and shell thickness of the developed shell models using an ultra-high performance concrete mix. The results are then compared to the upright case by simulating variable soil conditions including bearing soil shear strength and void ratio including loose, medium and dense sand states. The contact pressure distribution envelopes are developed for the bearing areas contact surface at the soil-structure interface.

\subsection{Soil Tested}

Grain size distribution curve of the Tech-Mix ${ }^{\circledR}$ sand used in the experimental phase is shown in Fig. 1 as compared with popular Ottawa Sand. The soil was classified as well-graded (SW) type sand according to the Unified Soil Classification System (USCS). The shear strength parameters and the maximum dry unit weight of the sand were obtained from direct shear and modified proctor tests. A summary of numerical input parameters is superimposed and various sand states are shown in Tables 1 and 2 . 


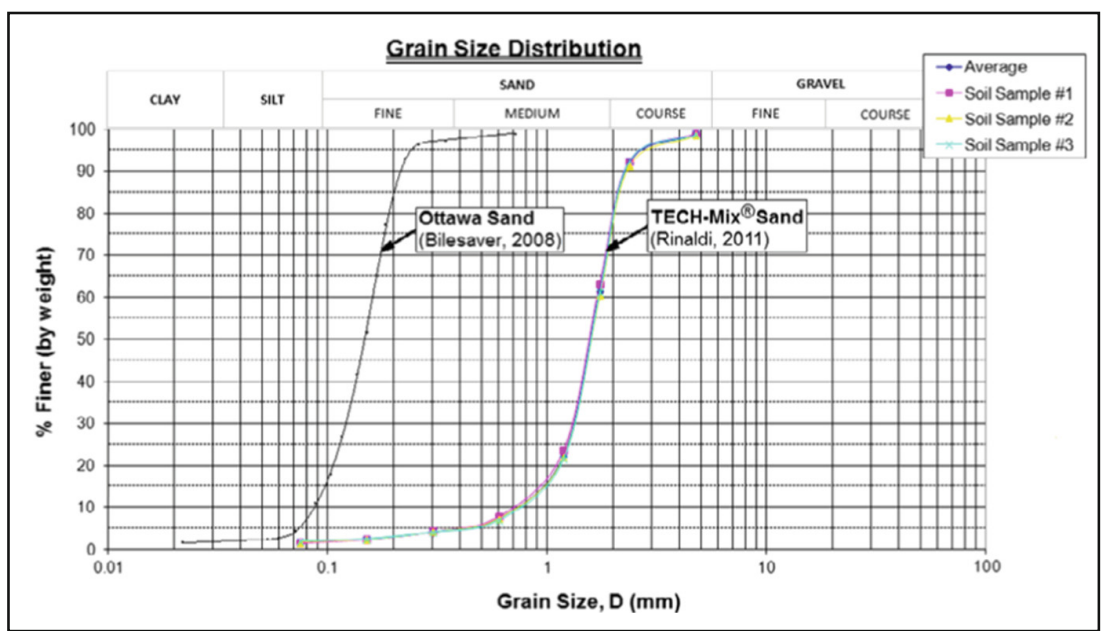

Fig. 1. Grain size distribution for sand

Table 1. Experimental sand's state

\begin{tabular}{l|l|l|l|l|l|l}
\hline & $\begin{array}{l}\text { Sand } \\
\text { state }\end{array}$ & $\begin{array}{l}\text { Dry } \\
\text { density, } \gamma_{\mathrm{d}} \\
\left(\mathrm{kN} / \mathrm{m}^{3}\right)\end{array}$ & $\begin{array}{l}\text { Porosity, } \\
\eta(\%)\end{array}$ & $\begin{array}{l}\text { Relative } \\
\text { density, } \mathrm{D}_{\mathrm{r}} \\
(\%)\end{array}$ & $\begin{array}{l}\text { Angle of shearing resistance, } \\
\phi\left(^{0}\right)\end{array}$ \\
\cline { 6 - 7 } & & $\begin{array}{l}\text { Direct shear } \\
\text { box test } \\
\text { results }\end{array}$ & $\begin{array}{l}\text { Triaxial } \\
\text { compression } \\
\text { test }\end{array}$ \\
\hline I & Loose & 16.15 & $48.9 \%$ & $33.6 \%$ & 32.63 & 28.94 \\
\hline II & $\begin{array}{l}\text { Medium } \\
\text { dense }\end{array}$ & 17.85 & $43.7 \%$ & $55.8 \%$ & 39.22 & 32.24 \\
\hline III & Dense & 18.75 & $38.1 \%$ & $79.2 \%$ & 42.71 & 35.82 \\
\hline
\end{tabular}

Table 2. TECH-Mix ${ }^{\circledR}$ sand's properties

\begin{tabular}{l|l|l|c}
\hline TECH-Mix ${ }^{\circledR}$ sand's properties & Value & TECH-Mix® sand's properties & Value \\
\hline Specific gravity, $\mathrm{G}_{\mathrm{s}}$ & 2.60 & Maximum void ratio, $\mathrm{e}_{\max }$ & 1.70 \\
\hline Coefficient of uniformity, $\mathrm{C}_{\mathrm{u}}$ & 2.42 & Minimum void ratio, $\mathrm{e}_{\min }$ & 1.43 \\
\hline Coefficient of curvature, $\mathrm{C}_{\mathrm{c}}$ & 1.83 & Relative density, $D_{r}(\%)$ & 50.8 \\
\hline Cohesion, $c(\mathrm{kPa})$ & 0.001 & $\begin{array}{l}\text { Peak angle of internal friction, } \\
\varnothing\left({ }^{\circ}\right)\end{array}$ & 35.1 \\
\hline $\begin{array}{l}\text { Grain diameter at } 10 \% \text { passing, } \mathrm{D}_{10} \\
(\mathrm{~mm})\end{array}$ & 0.70 & $\begin{array}{l}\text { Maximum dry density, } \\
\gamma_{\mathrm{d}, \max }\left(\mathrm{kN} / \mathrm{m}^{3}\right)\end{array}$ & 16.80 \\
\hline $\begin{array}{l}\text { Grain diameter at } 60 \% \text { passing, } \mathrm{D}_{60} \\
(\mathrm{~mm})\end{array}$ & 1.71 & $\begin{array}{l}\text { Minimum dry density, } \\
\gamma_{\mathrm{d}, \text { min }}\left(\mathrm{kN} / \mathrm{m}^{3}\right)\end{array}$ & 14.03 \\
\hline $\begin{array}{l}\text { Grain diameter at } 30 \% \text { passing, } \mathrm{D}_{30} \\
(\mathrm{~mm})\end{array}$ & 1.48 & \begin{tabular}{l} 
Optimum water content, w $(\%)$ \\
\hline
\end{tabular} & 12.30 \\
\hline
\end{tabular}




\subsection{Shell Material}

A fluid concrete mix was developed incorporating fiber reinforced polymers (FRP's) into its matrix by exploiting latest material technology as part of innovative solution destined for shell footings. Shell Mix is a Super Highly Engineered Light Liquid Mix (SHELL Mix®) which diverges from conventional concrete mixes by offering high-strength durability and remarkable structural performance. The mix has a reduced water-cement ratio of 0.25 and incorporates super plasticizers, fiber additives but no

\section{$\underline{\text { SHELL Mix }{ }^{\oplus} \text { Composition }}$}

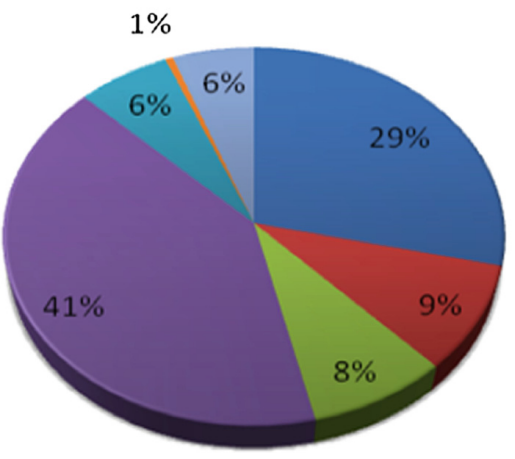

$\square$ Cement

$\square$ Silica Fume

$\square$ Ground Quartz

Fine Sand

$\square$ Organic/Metallic Fibers

$\square$ Superplasticizer

$\square$ Water

Fig. 2. Shell concrete mix composition

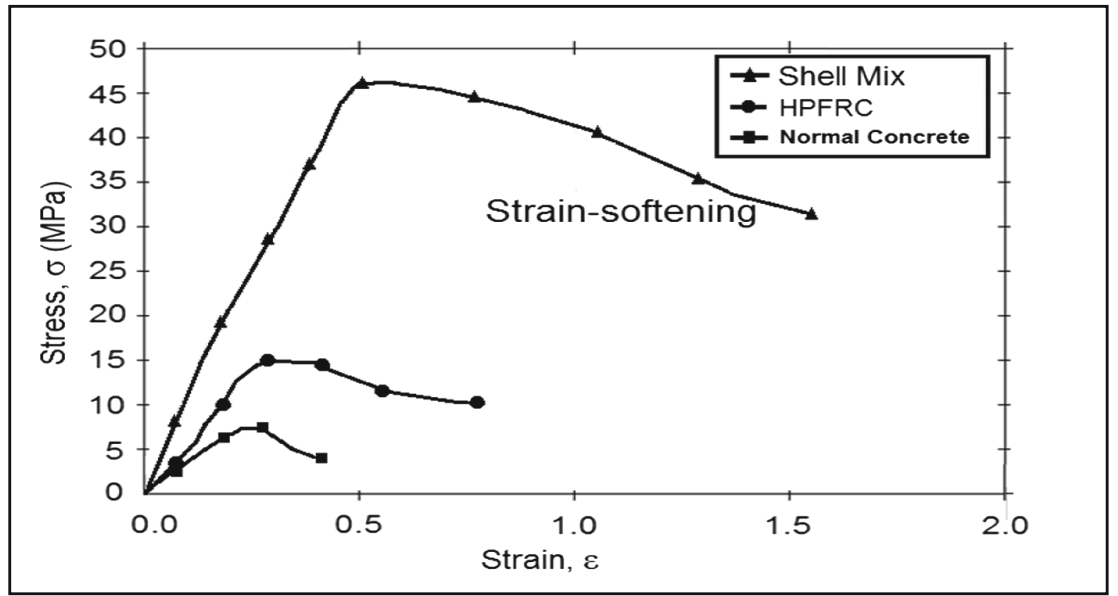

Fig. 3. Stress-strain curve for shell mix concrete 


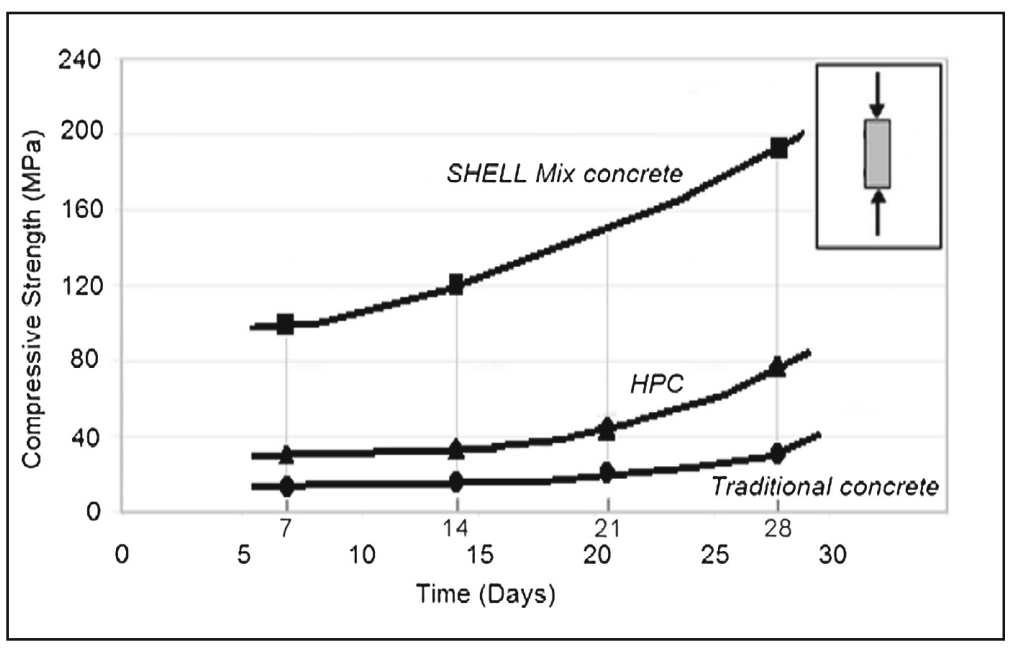

Fig. 4. Compression strength of shell mix concrete

aggregates. A breakdown of SHELL Mix composition (ingredients) is presented in Fig. 2. Stress-Strain curve and compression strength for the shell mix concrete are shown in Figs. 3 and 4, respectively.

\subsection{Footing Models}

Table 3 presents the geometrical data of the nine footing models used in the present experimental investigation (area, shell angels, shell thickness, radii of Gyration and moment of inertia) and Fig. 5 illustrates the geometrical configuration of the footing models. An overall view of the wood moulds used to cast the footing models and the cast concrete footing models are presented in Figs. 6 and 7, respectively.

\subsection{Test Set-up}

A plexiglass tank and a self-reacting A-frame housing was the test apparatus designed and built to load the shell footing models through a loading yoke employing ball-pinion and jack loading cylinder. The rectangular tank had internal dimensionso of $241.3 \mathrm{~mm} \times 1.15 \mathrm{~m} \times 2.30 \mathrm{~m}\left[9 \frac{1}{2}{ }^{\prime \prime} \times 45^{1 / 4}, " \times 901 \frac{1}{2} "\right.$ " $]$ with an overall test setup as illustrated in Fig. 8. 
Table 3. Geometrical properties of the nine footing models

\begin{tabular}{|c|c|c|c|c|c|c|c|c|}
\hline \# & \multirow[t]{2}{*}{ Shape ID } & \multirow[t]{2}{*}{$\begin{array}{l}\text { Area } \\
\left(\mathrm{mm}^{2}\right)\end{array}$} & \multirow[t]{2}{*}{$\begin{array}{l}\text { Shell angle } \\
\theta\left({ }^{0}\right)\end{array}$} & \multirow[t]{2}{*}{$\begin{array}{l}\text { Thickness } \\
\mathrm{T}_{\text {shell }}(\mathrm{mm})\end{array}$} & \multicolumn{2}{|c|}{$\begin{array}{l}\text { Radii of } \\
\text { gyration }\end{array}$} & \multicolumn{2}{|c|}{ Moment of inertia } \\
\hline & & & & & \begin{tabular}{|l|}
$r_{\mathrm{x}}$ \\
$(\mathrm{mm})$
\end{tabular} & \begin{tabular}{|l}
$\mathrm{r}_{\mathrm{y}}$ \\
$(\mathrm{mm})$
\end{tabular} & $\begin{array}{l}\mathrm{I}_{\mathrm{x}}\left(10^{6}\right. \\
\left.\mathrm{mm}^{4}\right) \\
\end{array}$ & $\begin{array}{l}\mathrm{I}_{\mathrm{y}}\left(10^{6}\right. \\
\left.\mathrm{mm}^{4}\right)\end{array}$ \\
\hline 1 & Flat & 8375.0 & 180 & 25 & 43.05 & 133.62 & 8.22407 & 28.92370 \\
\hline 2 & $\begin{array}{l}\text { Upright } \\
\text { triangular }\end{array}$ & 10167.0 & 34 & 25 & 79.81 & 135.05 & 13.84753 & 39.01845 \\
\hline 3 & $\begin{array}{l}\text { Inverted } \\
\text { sinusoidal }\end{array}$ & 8212.0 & 36 & 25 & 56.12 & 157.12 & 5.77006 & 4.88796 \\
\hline 4 & $\begin{array}{l}\text { Inverted } \\
\text { shell \#1 }\end{array}$ & 5652.3 & 18 & 19 & 32.06 & 142.03 & 1.43956 & 32.62395 \\
\hline 5 & $\begin{array}{l}\text { Inverted } \\
\text { shell \#2 }\end{array}$ & 6014.6 & 27 & 19 & 44.45 & 142.16 & 2.91641 & 34.94346 \\
\hline 6 & $\begin{array}{l}\text { Inverted } \\
\text { shell \#3 }\end{array}$ & 6529.5 & 36 & 19 & 58.42 & 142.17 & 5.55119 & 37.95048 \\
\hline 7 & $\begin{array}{l}\text { Inverted } \\
\text { shell \#4 }\end{array}$ & 6777.6 & 18 & 25 & 32.68 & 140.23 & 1.52102 & 35.68909 \\
\hline 8 & $\begin{array}{l}\text { Inverted } \\
\text { shell \#5 }\end{array}$ & 7205.1 & 27 & 25 & 43.79 & 140.37 & 3.10044 & 38.21459 \\
\hline 9 & $\begin{array}{l}\text { Inverted } \\
\text { shell \#6 }\end{array}$ & 7828.1 & 36 & 25 & 57.11 & 140.39 & 5.97969 & 41.55284 \\
\hline
\end{tabular}

\subsection{Test Procedure}

The test tank was filled using sand spreading technique from a $300 \mathrm{~mm}$ drop height and tamped in layers successively to obtain uniform compaction with a wooden plate measuring $600 \mathrm{~mm} \times 240 \mathrm{~mm}$ in plan. The pressure transducers were flush-mounted with the shell footing model's base to measure pressures at the shell-soil interface. This was carefully done to avoid any density variations leading to either stress concentration or relaxation. The footing models were each carefully placed with pre-excavated trench in the case of inverted shell ensuring full-contact with the models having a natural interface roughness simulating actual construction similitude.

Using a hydralic jack outfitted with a load cell, each of the footings were statically tested using montonic loading three times for a total of 27 tests. An iinitial axial compressive load of $0.2 \mathrm{kN}$ was applied directly to the loading yoke transferred forces to the edges beams at the toe of the shells continuing the applied load at uniform rate of $0.15 \mathrm{kN} / \mathrm{sec}$ for several minutes. Following all measurements, the load-settlement curve was plotted with the ultimate load obtained by the tangent method.

The miniature pressure transducers housed in custom metallic slot-plug adaptors measured soil pressure while vertical and horizontal soil displacements were controlled using a linear variable displacement transducers and measuring tape afixed directly to the tank. 


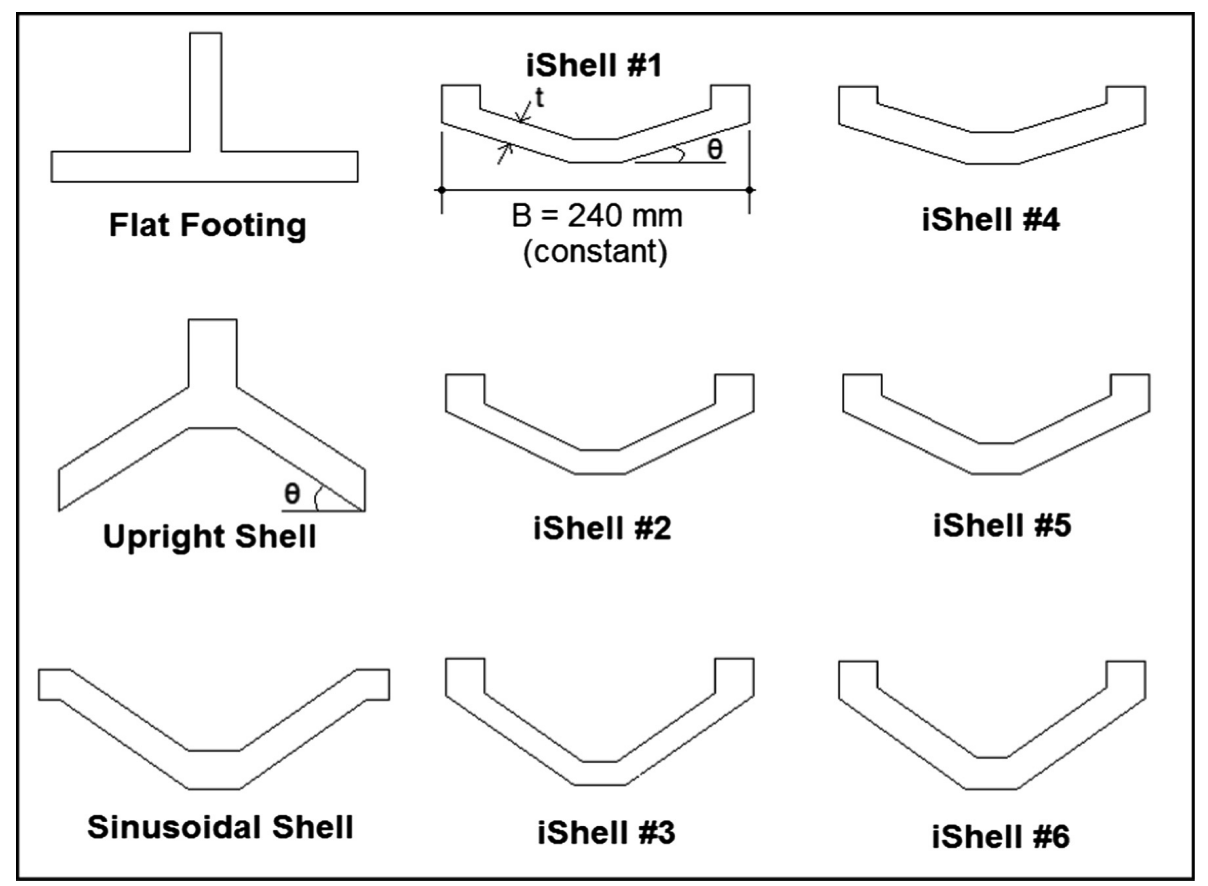

Fig. 5. Geometrical configuration of the nine tested footing models $(240 \mathrm{~mm} \times 240 \mathrm{~mm}$ in plan)

\subsection{Test Results}

The ultimate loads and settlement behavior of the inverted shell test models (iShell \#1 to iShell \#6) are analyzed and compared to that of the flat and upright and sinusoidal shell models. In the analysis and prediction of performance, a Shell Efficiency factor, $\eta_{\text {is }}$ and a Settlement factor, $F_{\delta(\text { is })}$ are defined for the inverted shell as presented in the following equations:

$$
\begin{gathered}
\eta_{i s}=\left(\frac{\mathrm{Q}_{\mathrm{is}}-\mathrm{Q}_{f}}{\mathrm{Q}_{u s}-\mathrm{Q}_{f}}\right)_{u} \\
\mathrm{~F}_{\delta(\mathrm{is})}=\left(\frac{\delta \gamma \mathrm{A}_{p}}{\mathrm{Q}_{\mathrm{u}}}\right)_{u}
\end{gathered}
$$

Where:

$\eta_{\text {is: }}$ : shell efficiency factor

$\mathrm{Q}_{\text {is: }}$ failure load for inverted shell model $(\mathrm{kN})$

$\mathrm{Q}_{\mathrm{f}}$ : failure load for flat model $(\mathrm{kN})$

$\mathrm{Q}_{\mathrm{us}}$ : ultimate load for shell model $(\mathrm{kN})$

$\mathrm{F}_{\delta(\mathrm{is})}$ : settlement factor

$\delta$ : $\quad$ settlement $(\mathrm{mm})$ 


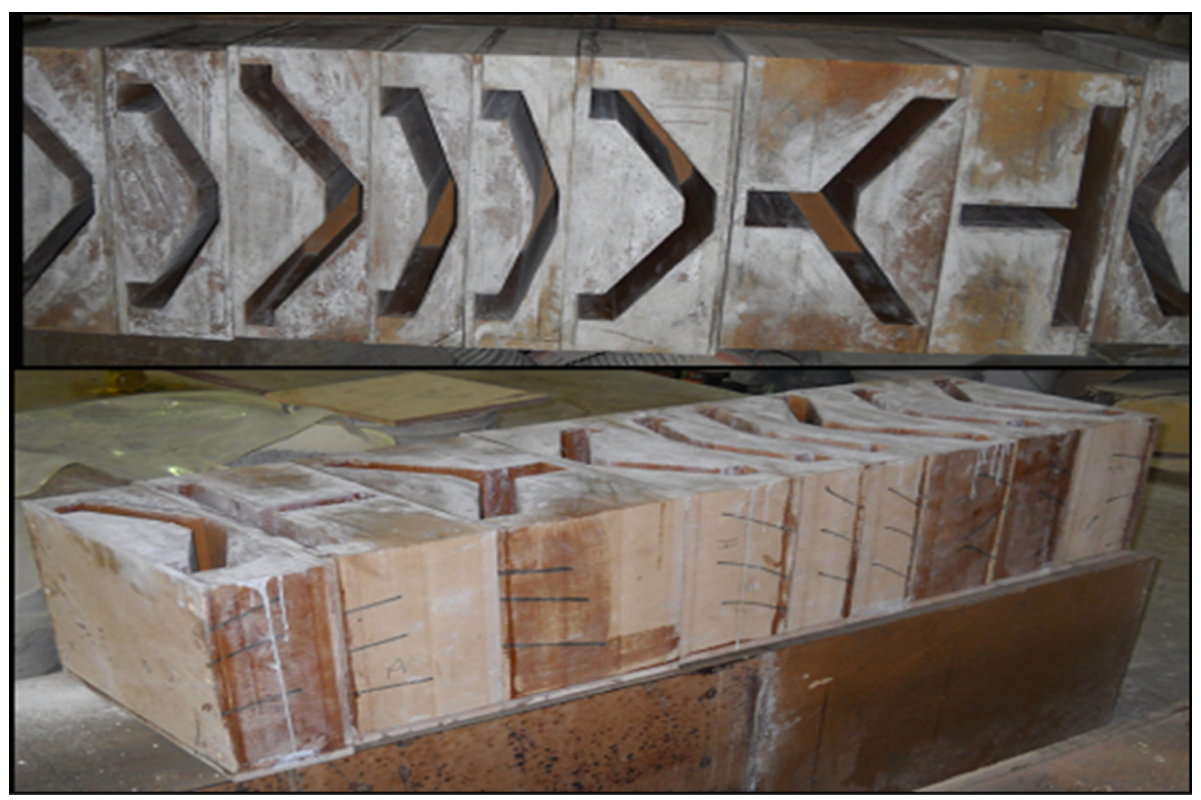

Fig. 6. Wood moulds used to cast the flat and shell footing models

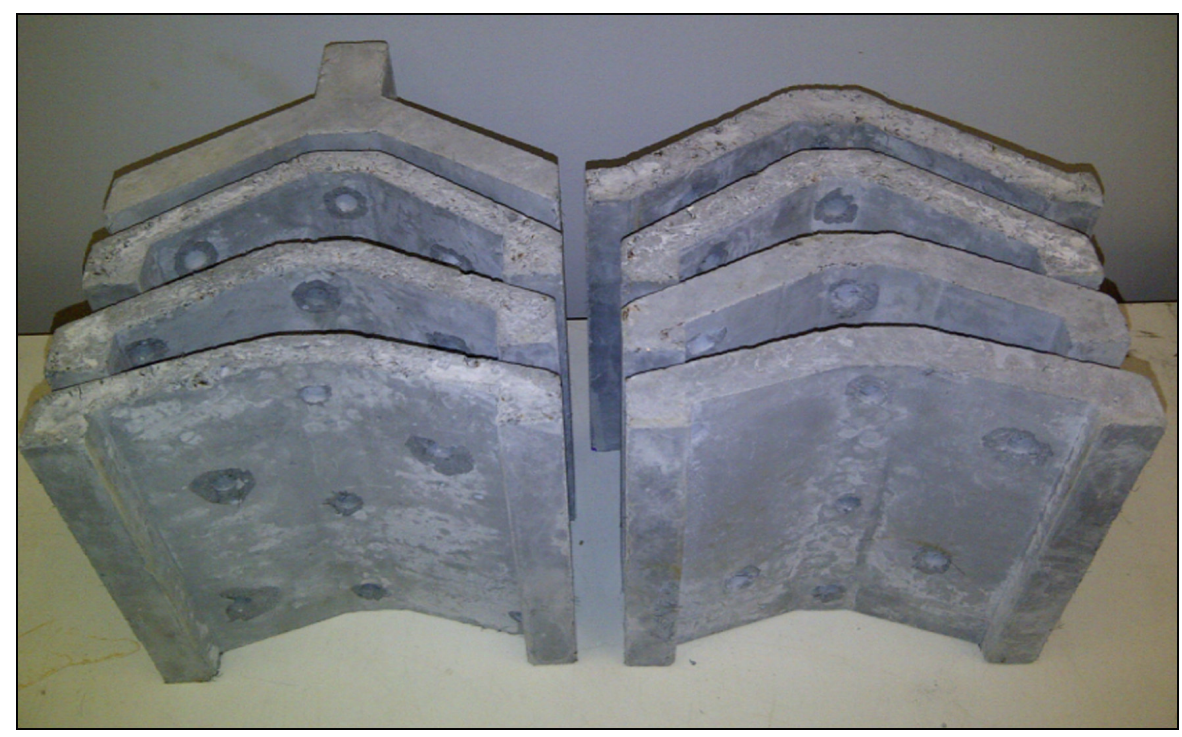

Fig. 7. Overall view of casted shell footing models made of mix concrete 


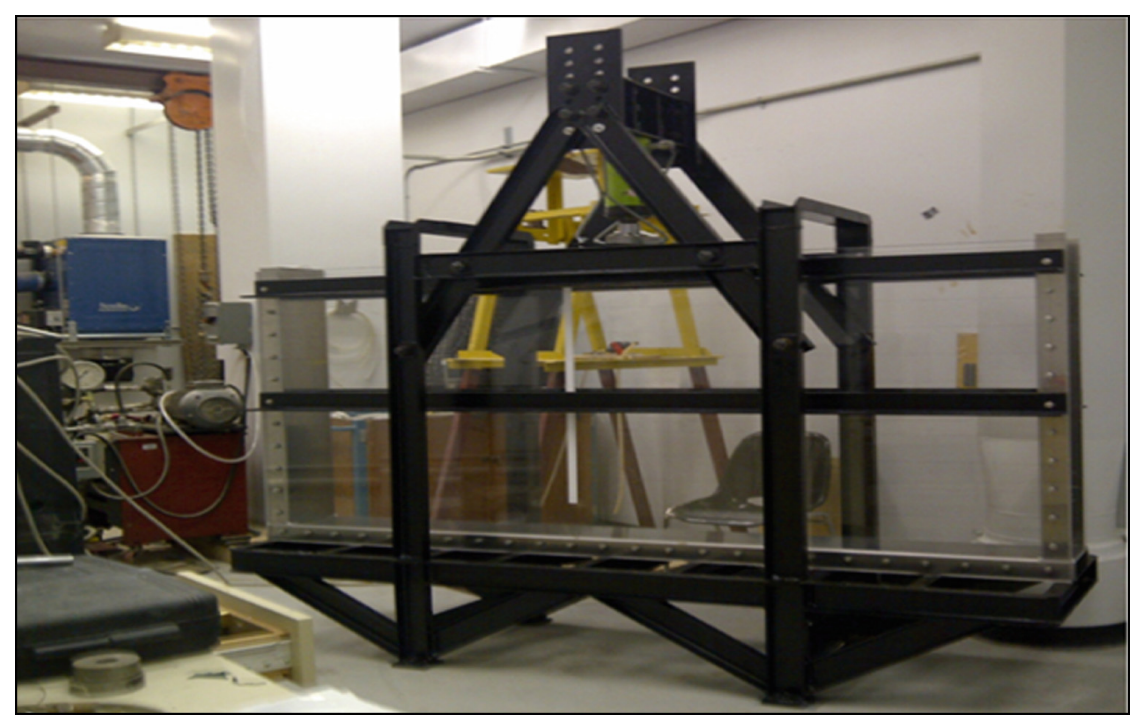

Fig. 8. Overall testing tank and frame setup

$\gamma: \quad$ soil unit weight $\left(\mathrm{kN} / \mathrm{m}^{3}\right)$

$\mathrm{A}_{\mathrm{p}}$ : area of planar shell footing projection $\left(\mathrm{m}^{2}\right)$

$\mathrm{Q}_{\mathrm{u}}$ : $\quad$ ultimate load $(\mathrm{kN})$

Typical obtained load-settlement curves from the experimental tests results for iShell footing models are presented in Fig. 9(a) and (b). The experimental results indicate that the efficiency of inverted shell footings $\left(\eta_{\text {is }}\right)$ decreases with increasing the angle of shearing resistance of the soil. That is, more compact and dense the soil becomes, the less beneficial shell footings become. This confirms the premise that shells are potentially better performers best suited for weaker soils that necessitate a large load transferred to them.

In terms of settlement, the factors of settlement indicate that the sinusoidal shell model has best settlement characteristics having the lowest $\mathrm{F}_{\delta}$. The inverted shells showed similar tendency, as their plots were in proximity with a 3\% spread. All models showed better settlement behavior as the soils angle of shearing resistance increased as intuitively expected. It is generally observed that the inverted shells have better performance of the order of 3-9\% over the upright shell and $12-18 \%$ better performance to that of their flat counterparts. Figure 10 presents samples of the load settlement curves for three footing models and Fig. 11 illustrates the variation of the ultimate load with the angle of shearing resistance for all nine tested footing models.

Typical rupture surfaces observed during experimental phase for flat and upright shell foundation models and Sinusoidal and iShell Models are shown in Figs. 12 and 13 , respectively. 

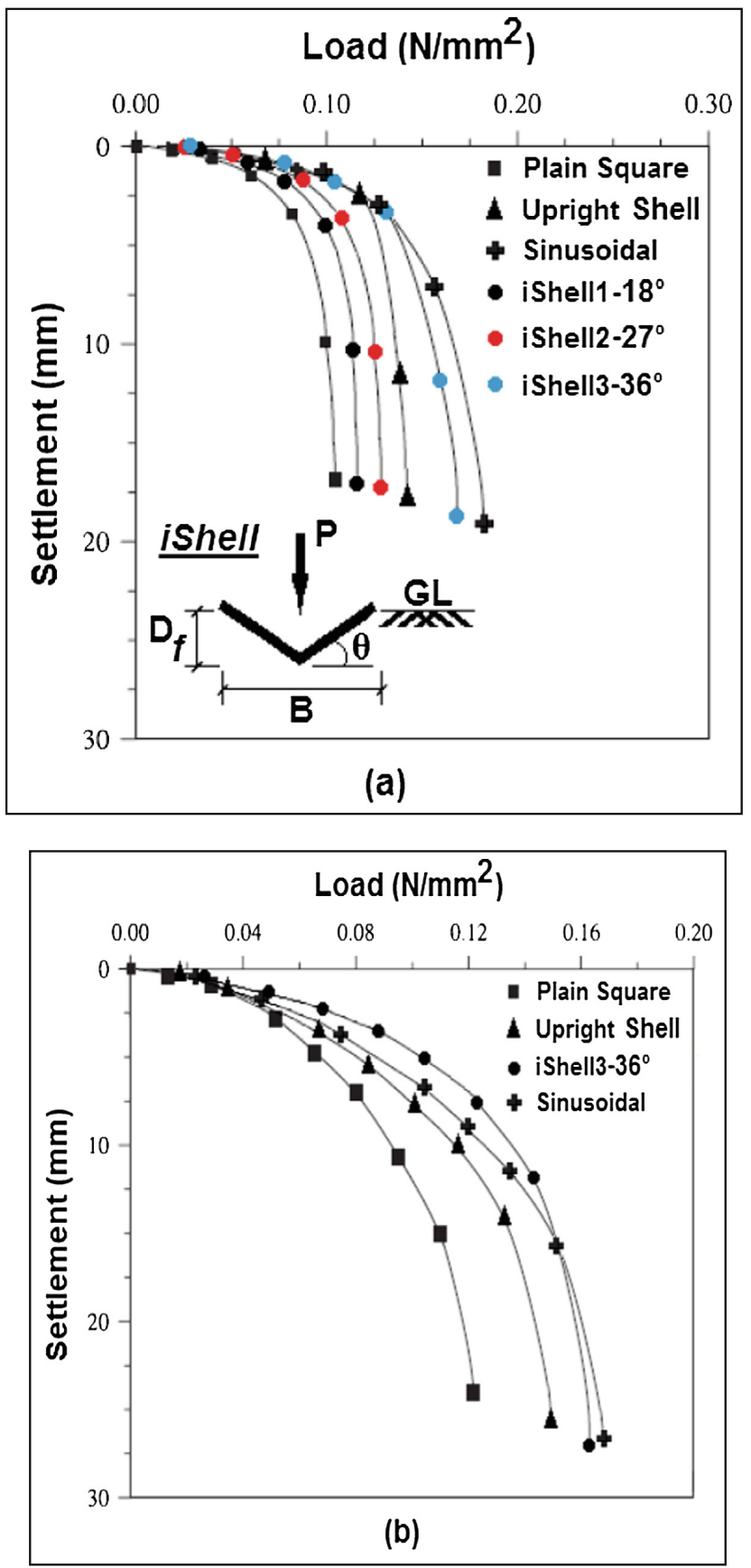

Fig. 9. Load-settlement curves for iShell footing models 


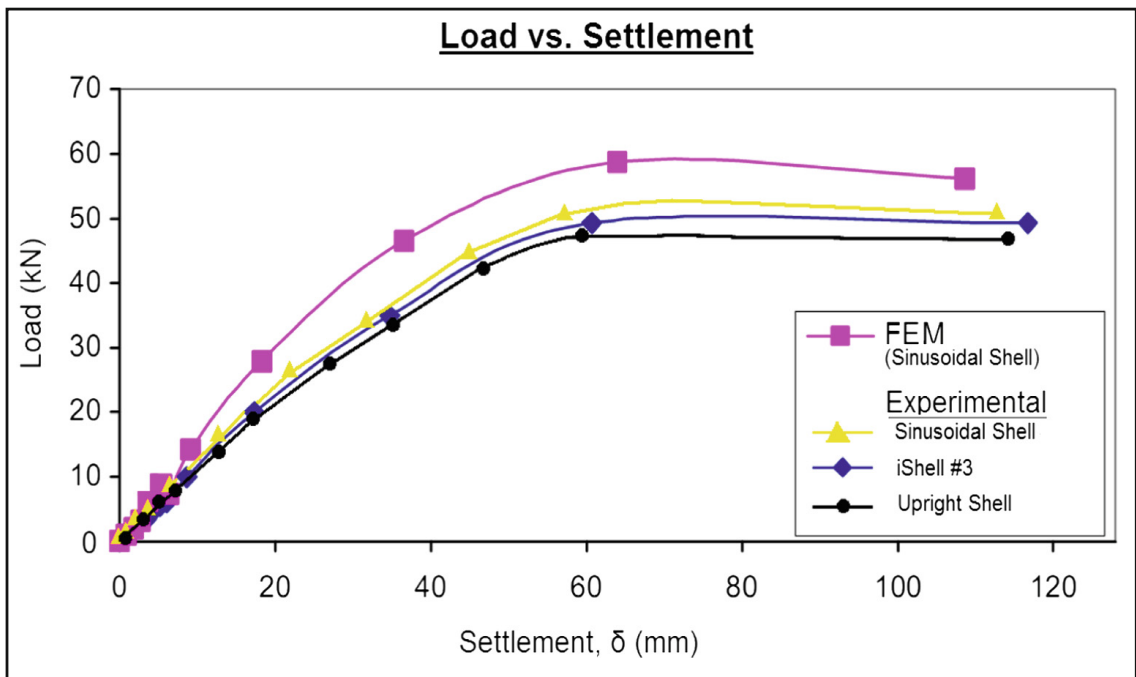

Fig. 10. Load vs. settlement for upright and triangular strip iShell footings

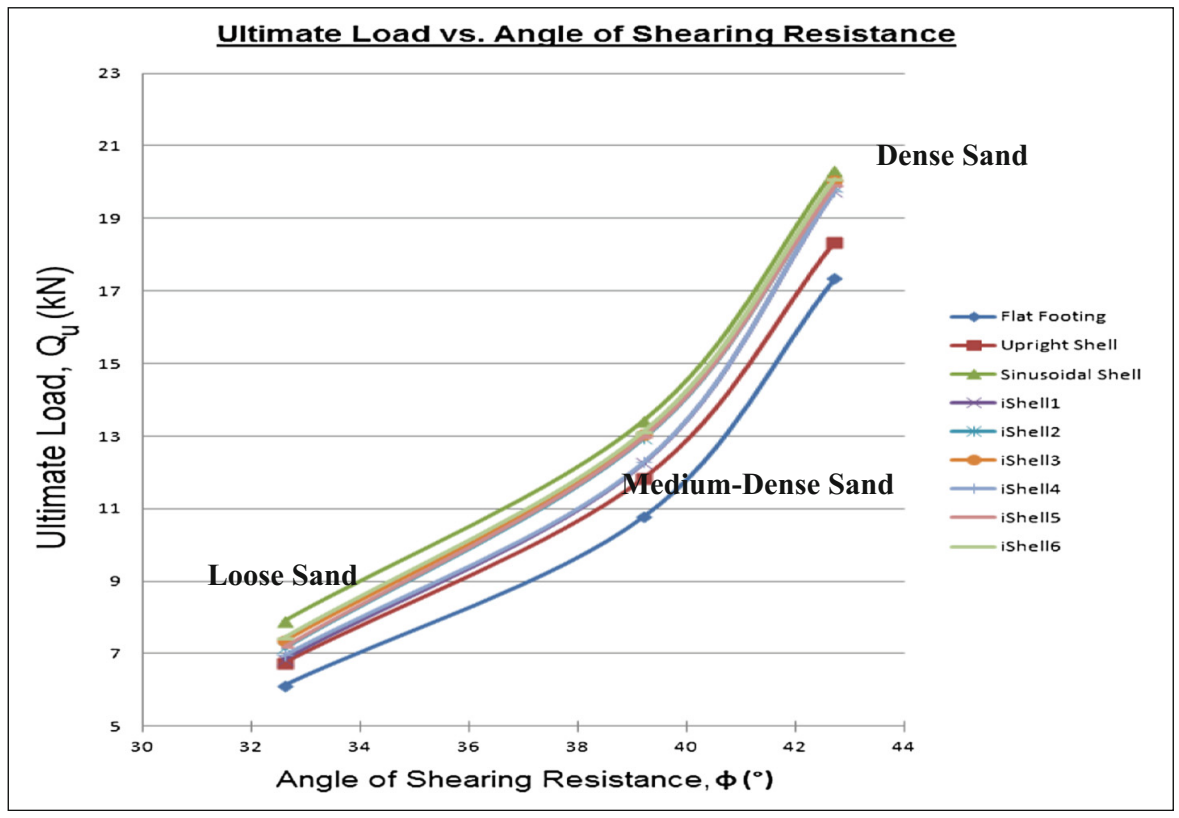

Fig. 11. Ultimate load $\left(\mathrm{Q}_{u}\right)$ vs. angle of shearing resistance, $\phi\left(^{\circ}\right)$ 


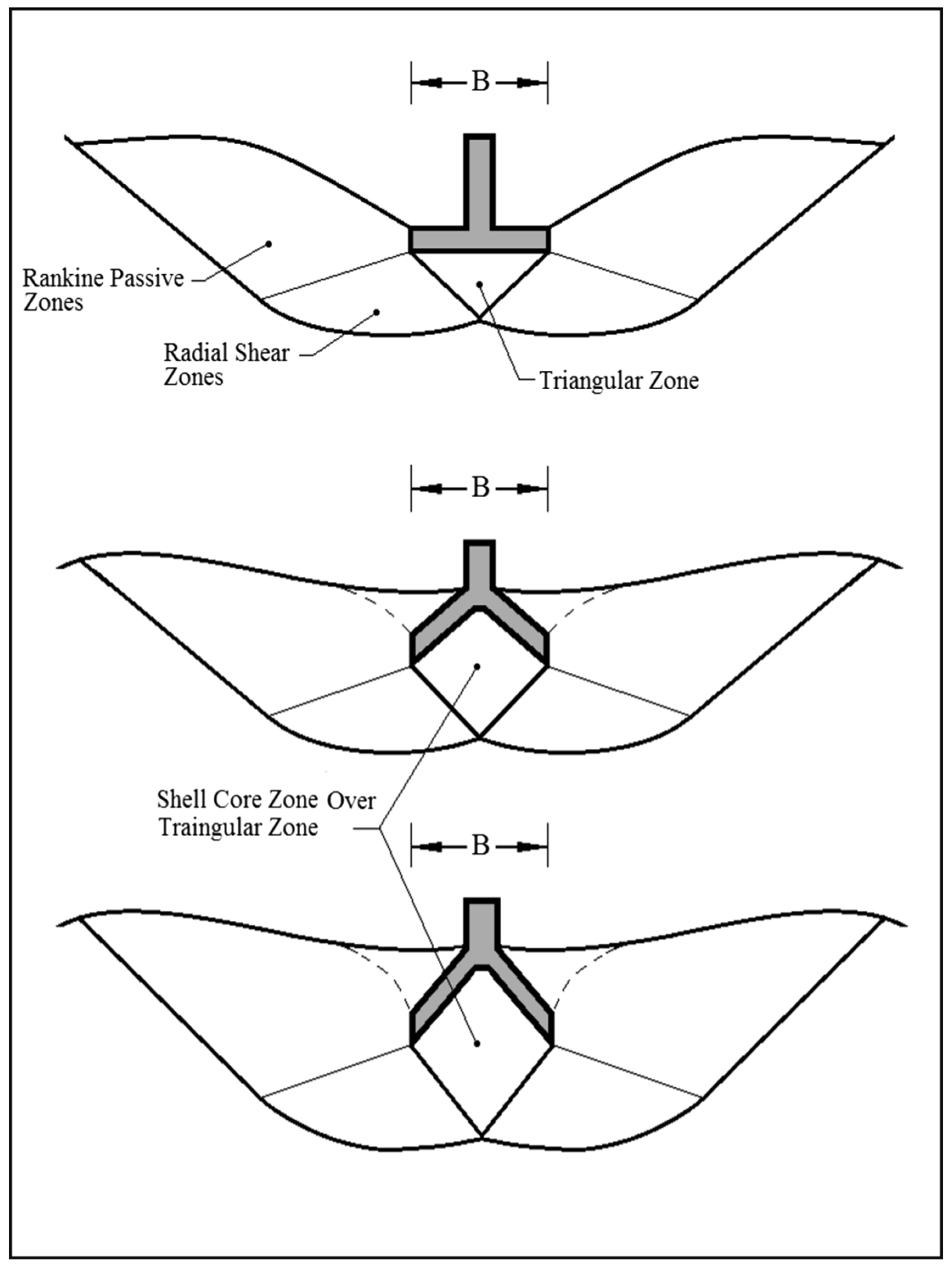

Fig. 12. Rupture surfaces for flat and upright shell foundation models 


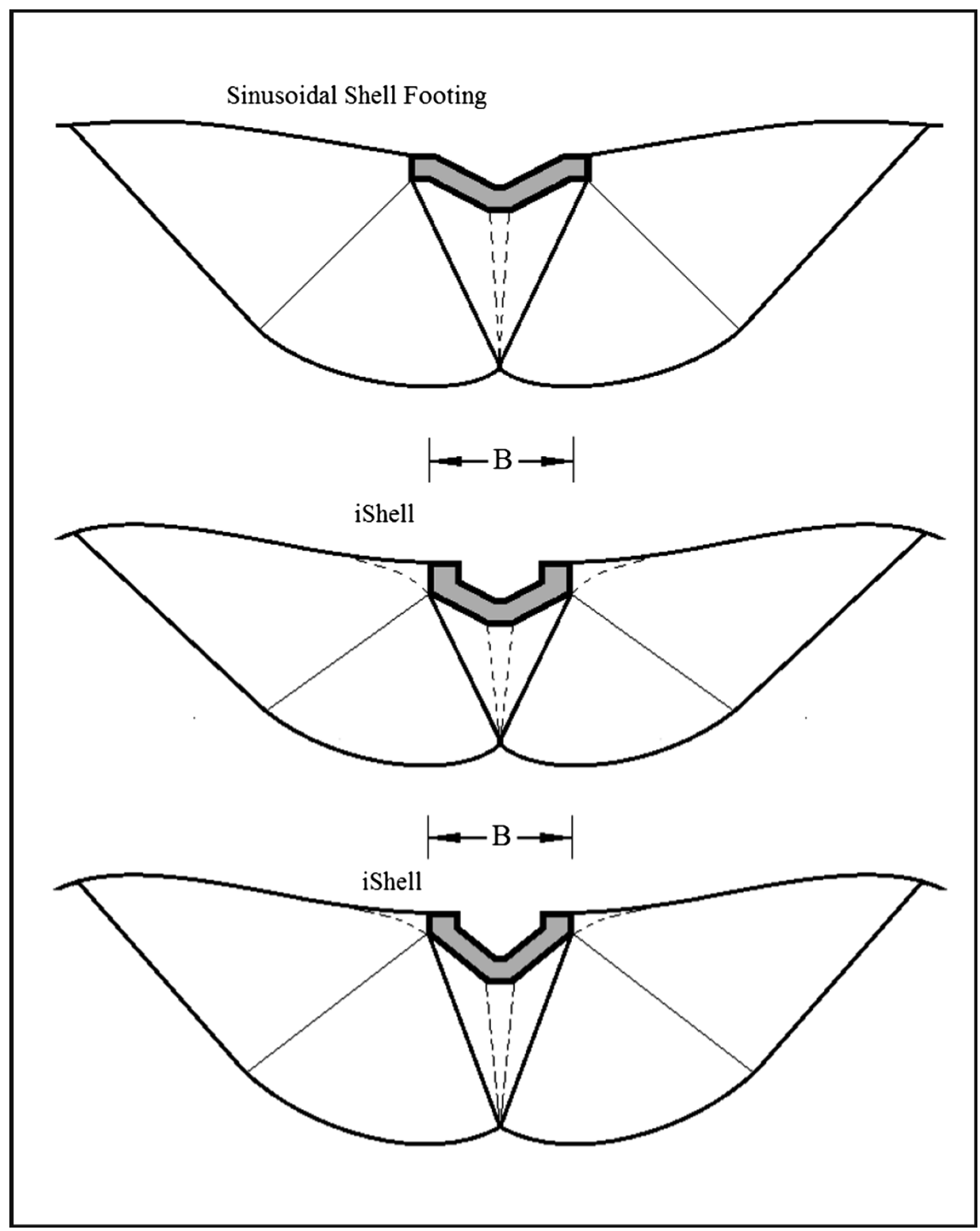

Fig. 13. Rupture surfaces for sinusoidal and iShell foundation models 


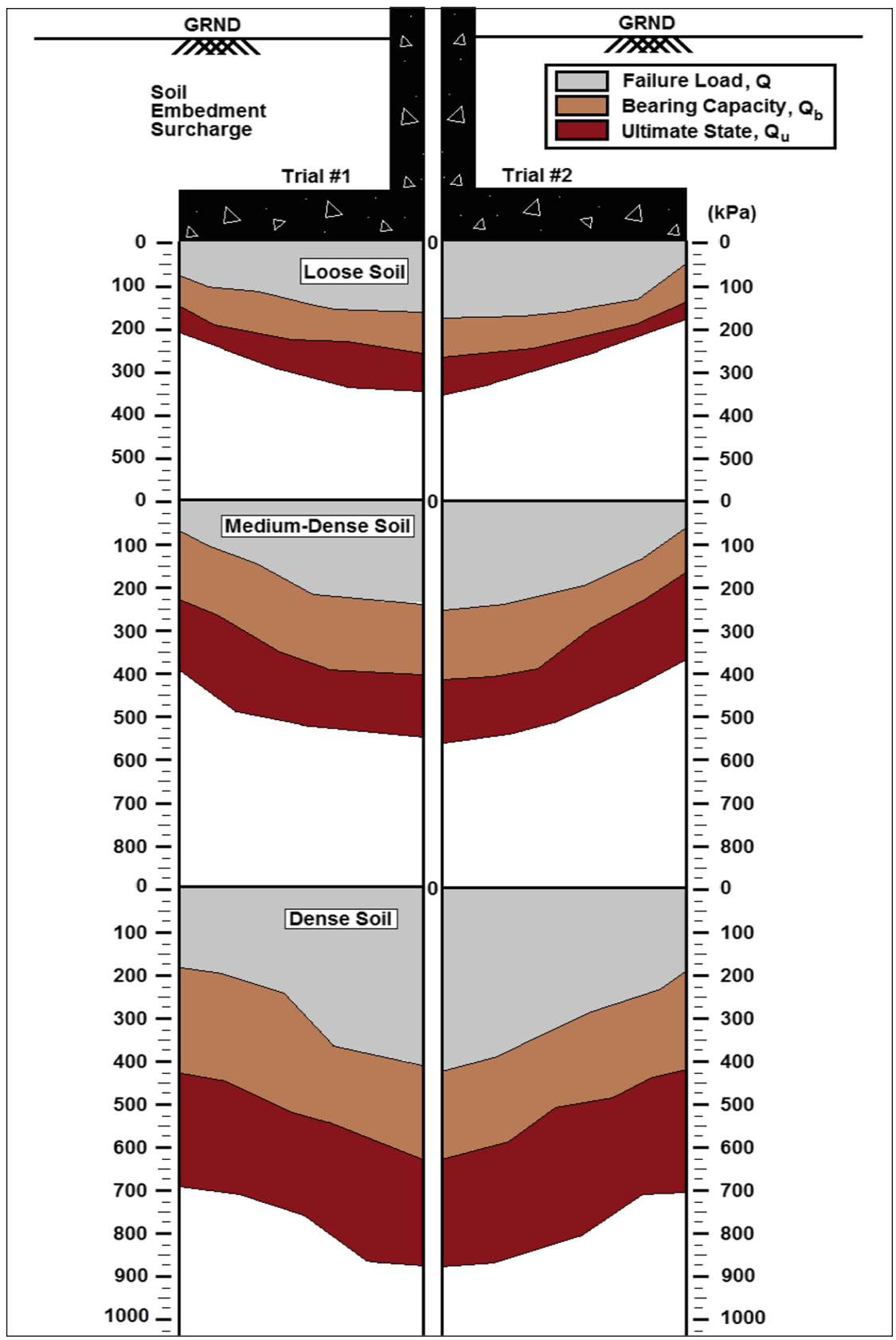

Fig. 14. Contact pressure distribution for flat footing model 


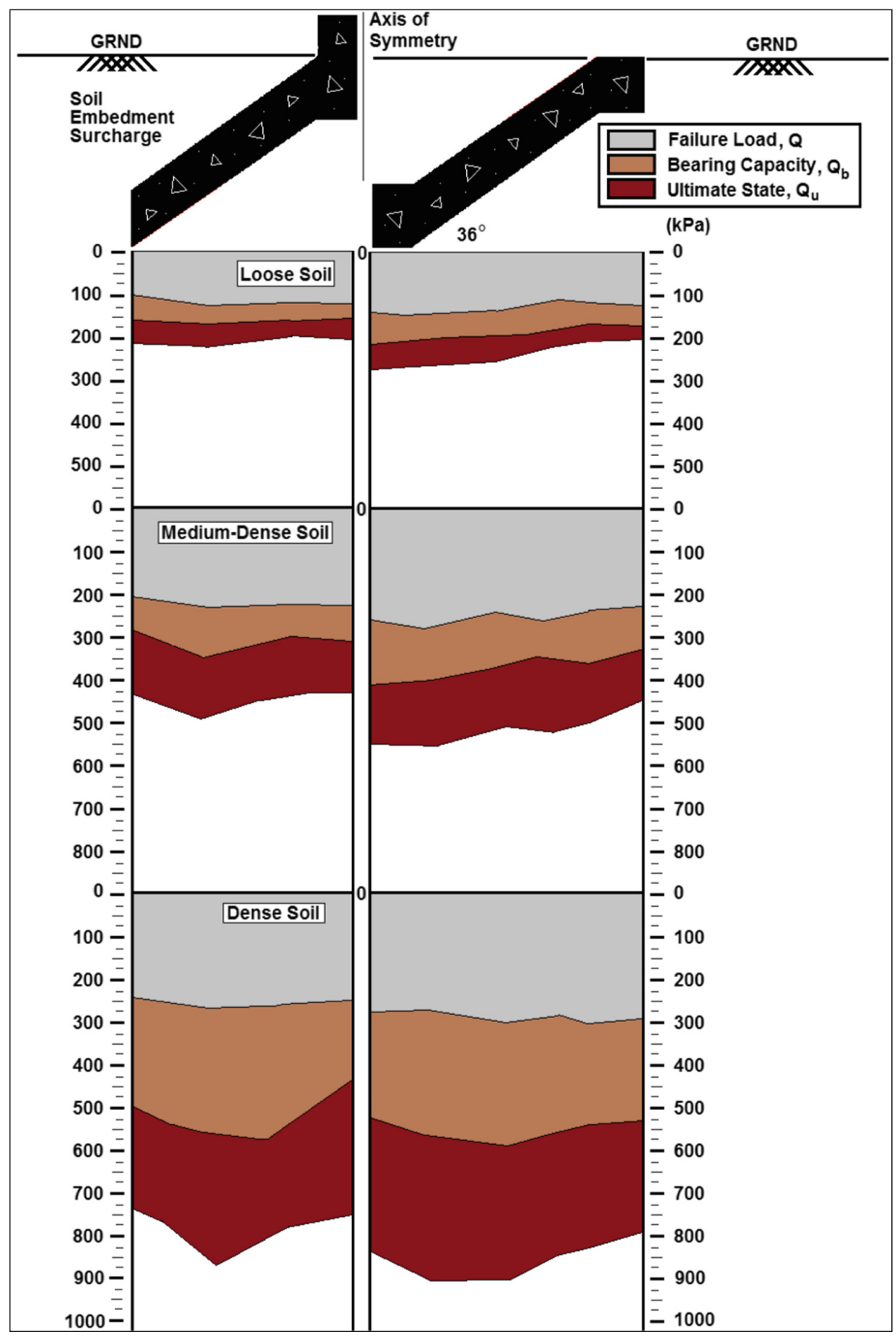

Fig. 15. Contact pressure distribution for upright and sinusoidal shell models 


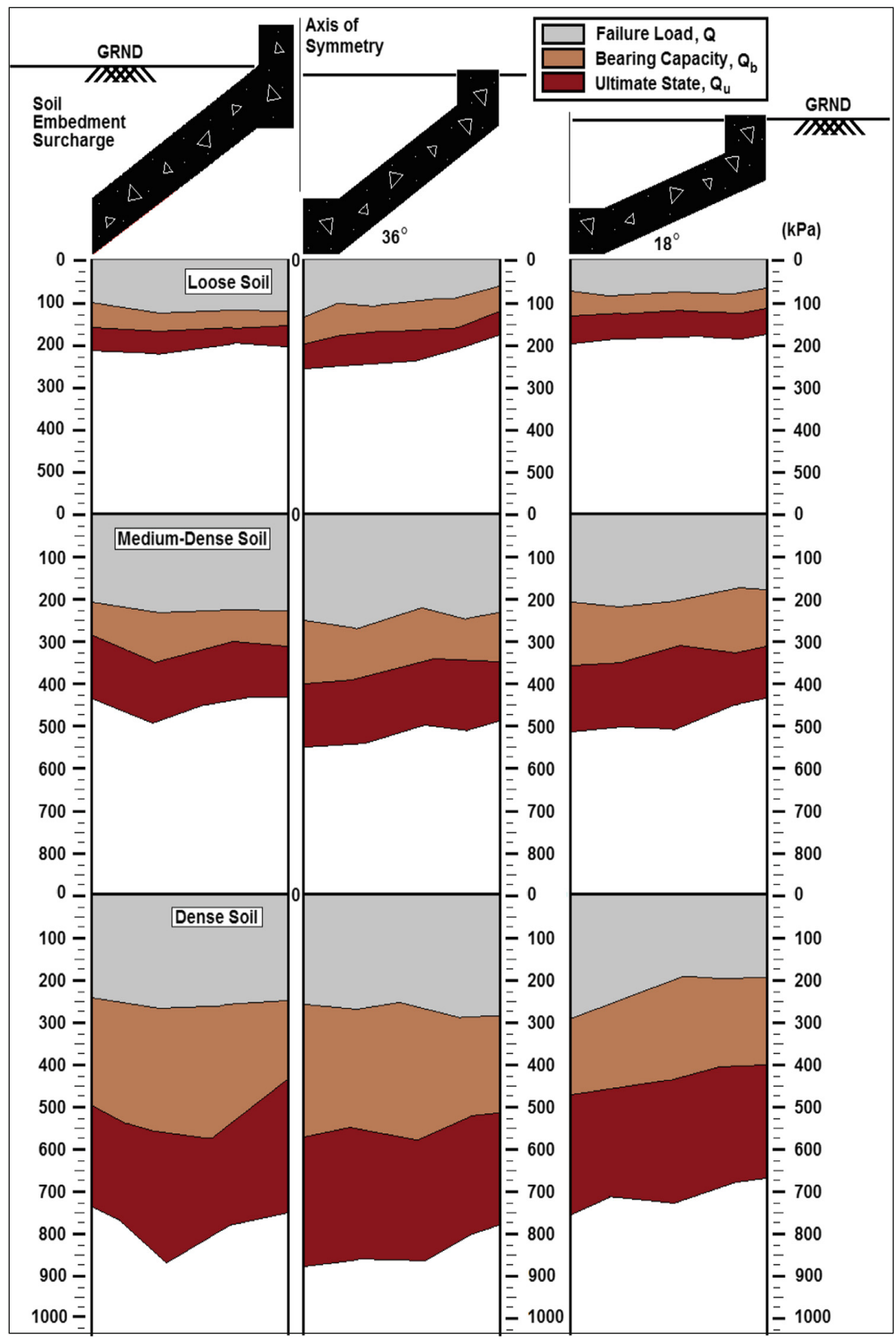

Fig. 16. Contact pressure distribution for iShell18 ${ }^{\circ}$ (iS4) \& iShell36 ${ }^{\circ}$ (iS6) models 
Finally, contact pressures are measured during the experimental investigation for three sand states (loose, medium-dense, and dense) and the results are presented in Figs. 14, 15 and 16 in terms of failure load, bearing capacity and ultimate state load.

\section{Conclusions}

Experimental investigation was conducted on nine footing models, including one upright, one sinusoidal, one flat and six inverted shells, the following conclusions are drawn:

(1) The load-carrying capacity of shell footing shows an average $40-45 \%$ higher load-carrying capacity than its existing flat counterpart with slightly better improvement of 5\% over the upright shell case under identical soil and loading conditions, thereby establishing the superiority of shell configuration over its plain and upright counterparts.

(2) Beneath shell footings and also under flat ones, an increase in load bearing capacity is experienced with increasing density of sand (based on $c-\phi$ soil strength parameters). The performance of shell footings is dependent on the shape of the shell used inducing a shell-soil interface primarily based on shell angle and the quality of the concrete material employed.

(3) Effect of shell angle on the footings capacity is a major factor in performance as an increase of only $18^{\circ}$ in shell angle translated to a $12 \%$ increased load - carrying capacity.

(4) Contact pressure distribution were measured during experimental investigation using pressure transducers and presented for different sand state for all tested iShell and flat models and the results are presented under failure load, bearing capacity and ultimate state.

(5) The contact pressure indicates a tendency for edge concentrations in the elastic stages of loading. The rigid edge beams absorb the load in this initial stages would be reason for their attention and application in the design stages of the shell footing. As loading continues a tendency for contact pressure may shift to the shell core regions in the inelastic stages.

\section{References}

1. Agarwal, K.B., Gupta, R.N.: Soil-structure interaction in shell foundations. In: Proceedings of the International Workshop on Soil Structure Interaction, University of Roorkee, Roorkee, India, vol. 2, pp. 110-112 (1977)

2. Hanna, A., Abdel-Rahman, M.: Experimental investigation of shell foundations on dry sand. Can. Geotech. J. 35(5), 847-857 (1998)

3. Hanna, A., El-Rahman, A.: Ultimate bearing capacity of triangular shell strip footings on sand. ASCE J. Geotech. Eng. 116(12), 1851-1863 (1990)

4. Iyer, T.S.R., Rao, N.R.: Model studies on funicular shells as rafts on sands. In: Proceedings of the Symposium on Shallow Foundations (1970) 
5. Kurian, N.P., Jeyachandran, S.R.: Model studies on the behavior of sand under two and three dimensional shell foundations. Indian Geotech. J. 2(1), 79-90 (1972)

6. Kurian, N.P., Jayakrishna Devaki, V.M.: Analytical studies on the geotechnical performance of shell foundations. Can. Geotech. J. 42(2), 562-573 (2005)

7. Kurian, N.P., Mohan, C.S.: Ultimate strength of hyperbolic parabolic shell foundations under vertical loads and moments. Bull. Int. Assoc. Shell Spat. Struct. 24-1(81), 27-42 (1983)

8. Kurian, N.P., Mohan, C.S.: Contact pressures under shell foundations. In: Proceedings of the International Conference on Soil Mechanics and Foundation Engineering, vol. 2, pp. 165168 (1981)

9. Kurian, N.P., Shah, S.H.: Economy of conical and inverted dome shell foundations. J. Inst. Eng. (India) Part CI: Civ. Eng. Div. 64, 281-286 (1984)

10. Rinaldi, R.: Inverted shell foundations in stochastic soil. Ph.D. thesis, Concordia University, Montreal, Canada (2012)

11. Varghese, P.C., Kurian, N.P.: Strength and performance of reinforced concrete precast hyperbolic footings. Indian Institute of Technology, Madras, pp. 49-66 (1971) 